\title{
UItra-SAXS observation of fibril-sized structure formation after the necking of poly (ethylene terephthalate) and poly(phenylene sulfide) fibers
}

\begin{tabular}{|l|l|}
\hline 著者 & $\begin{array}{l}\text { Tomisawa, Ren; Ando, Takumi; Ikaga, Toshifumi; Kim, } \\
\text { Kyounghou; Ohkoshi, Yutaka; Okada, Kazuyuki; Masunaga, } \\
\text { Hiroyasu; Kanaya, Toshiji; Katsuta, Hiroo; Funatsu, } \\
\text { Yoshitsugu }\end{array}$ \\
\hline 出版者 & NATURE PUBLISHING GROUP \\
\hline 引用 & POLYMER JOURNAL. 51(2):211-219(2018) \\
\hline 発行年月日 & $2018-11-09$ \\
\hline DOI & https://doi. org/10. 1038/s41428-018-0143-6 \\
\hline URL & http $: / /$ hdl. handle. net/10091/00022223 \\
\hline
\end{tabular}




\title{
Ultra-SAXS observation of fibril-size structure formation after the necking of poly(ethylene
} terephthalate) and poly(phenylene sulfide) fiber

\author{
R. Tomisawa ${ }^{1}$, T. Ando ${ }^{1}$, T. Ikaga ${ }^{1}$, K. H. Kim ${ }^{1 *}$, Y. Ohkoshi ${ }^{1,2}$, K. Okada $^{3}$, \\ H. Masunaga ${ }^{4}$, T. Kanaya ${ }^{5}$, H. Katsuta ${ }^{6}$ and Y. Funatsu ${ }^{6}$
}

${ }^{1}$ Faculty of Textile Science and Technology, Shinshu University, 3-15-1 Tokida, Ueda, Nagano 386-

$$
\begin{gathered}
\text { 8567, Japan. } \\
\text { E-mail: Khkim@shinshu-u.ac.jp }
\end{gathered}
$$

${ }^{2}$ Division of Frontier Fibers, Institute for Fiber Engineering, Shinshu University, 3-15-1Tokida

Ueda, Nagano prefecture, 386-8567, Japan.

${ }^{3}$ Material Science Laboratories, Toray Research Center, Inc., 3-3-7 Sonoyama, Otsu, Shiga 5208567, Japan.

${ }^{4}$ Japan Synchrotron Radiation Research Institute, 1-1-1 Kouto, Sayo-cho, Sayo-gun, Hyogo 679-

5148, Japan.

${ }^{5}$ High Energy Accelerator Research Organization, 203-1 Shirakata, Tokai-mura, Naka-gun, Ibaraki, 319-1106, Japan.

${ }^{6}$ Toray Industries, Inc., 4845 Mishima, Shizuoka 411-8652, Japan.

First Author; Ren Tomisawa, 16st106j@shinshu-u.ac.jp

Corresponding Author; KyoungHou Kim

\begin{abstract}
The fibril-size structure, which exhibits a density fluctuation of several tens to hundreds of nanometers, is important because it influences many properties of fibers and films, in particular, the strength and thermal shrinkage of synthetic fibers. We analyze the formation of the fibril-size structure after necking using ultra-small-angle X-ray scattering (USAXS), which enables observation of the void and craze formations. Continuous laser-heated drawing and undulator synchrotron radiation are adopted to measure the structural development of poly(ethylene terephthalate) (PET) and poly(phenylene sulfide) (PPS) fibers. Both fibers show an obvious increase in the meridional streak intensity just after necking, and an increase in the equatorial streak after necking. These increases are distinctive for PPS. Moreover, a layer-lined streak appeared after necking only for PET. The intensity of the meridian streak increased with the increase of draw ratio, whereas the intensity of layer-lined scattering decreased with the increase of draw ratio.
\end{abstract}


Keyword: USAXS, fibril-size structure, poly(ethylene terephthalate), poly(phenylene sulfide) Running Head: USAXS OBSERVATION OF FIBRIL-SIZE STRUCTURE FORMATION

\section{Introduction}

It is known that the strength and Young's modulus of synthetic fibers are greatly improved by orientation-induced crystallization during spinning and drawing. However, the strength of the obtained fiber is only about a few percent of the theoretical strength of perfect crystals [1]. This mainly arises from the fact that large amorphous regions remain in the fine structure of the fiber, and the structure is non-uniform. According to the weak link theory [2], generally for brittle materials, the failure depends on the strength of the weakest part. However, for ductile polymeric materials, the strength is not determined only by weak points; that is, the defects are propagated in the fiber structure by the drawing and thus the strength is determined by the degree of dispersion of the weak points.

In discussing the uniformity of entanglement structures, it is essential to understand the internal hierarchical structure of synthetic fibers. In the hierarchical structure of synthetic fibers, several nanometers scale structures (microfibril structure) [3-5] are observed in several hundred nanometers scale structures (macrofibril structures) [5-7]. The weakest point structure is probably caused by the interface of this hierarchical structure and thus the fiber strength can be improved by increasing the uniformity of the hierarchical fibrillar structure.

The typical fiber structure development of poly(ethylene terephthalate) (PET), that is, structure formation during spinning and drawing, has been intensely researched. Kolb et al. [8] measured the orientation-induced crystallization with a time resolution of 0.3-0.6 ms in the high speed spinning of PET fibers taken-up at $4000 \mathrm{~m} / \mathrm{min}$. Mahendrasingam et al. [9] and Kawakami et al. [10] studied the structural change during the batch drawing of a PET film. More recently, Okada et al. [11] obtained $\mathrm{X}$-ray images in the through and edge directions of a uniaxially drawn PET film, and investigated the differences in the structural changes in each direction. In the edge image, shear deformation was observed as a shear band-like structure formed by stacking benzene rings. Yamaguchi et al. [12] also observed a fibrillar smectic structure of several nanometers in diameter and several tens of nanometers in length within 1 ms after drawing, which was a long-period structure of approximately 4-5 periods. This smectic structure was considered to be the precursor of a microfibrillar structure. From our previous research [13] coupled with that of Yamaguchi, the amounts of smectic phase and d-spacing during drawing of PET fibers were analyzed in more detail. As a result, the fiber strength was observed to be determined by the amount and orientation of the inter-microfibrillar tie-chains linking the smectic phase, not the microfibrillar structure itself. Therefore, it is important for the fiber strength that the entangled network of molecular chains bears the strength efficiently. However, these studies only focused on the several nanometer-scale structures, and the influence of microfibrils and shear bands on the uniformity of fibrils was not examined. 
The structure and properties of poly(phenylene sulfide) (PPS) have also been studied [14-18]. PPS can easily form a rigid amorphous phase [19] because of its rigid molecular chain compared with that of PET, and there is little difference between the crystal and amorphous regions. The fiber structure model of PPS has been proposed by E. Perret et al. [18]. Recently, Ide et al. revealed the fiber structure development process during drawing of PPS fiber [20], and it was reported that PPS forms orthorhombic crystals through the pseudo-hexagonal mesophase. The X-pattern appeared at the initial stage of structure formation in SAXS, and it changed to the 4-point pattern with elapsed time. However, the analysis of several tens to hundreds of nanometers scale structures is still lacking. In this study, we attempted to obtain the ultra-small angle X-ray scattering (USAXS) image on the continuous drawing of the PET and PPS fibers. Very strong X-ray beam generated by synchrotron radiation equipped an undulator was used for the measurement. The fibrillar structure, which was several tens to hundreds of nanometers in diameter, was analyzed by the USAXS image.

\section{Experimental}

\subsection{Sample}

The fibers used for drawing were prepared by melt-spinning of PET (IV=1.32 dL/g) and PPS (MFR=120 g/10 min) provided by the Toray Co. The PET polymer was heated at $300{ }^{\circ} \mathrm{C}$ and the PPS polymer was heated at $330^{\circ} \mathrm{C}$. Both polymers were extruded from a one-hole nozzle at a mass flow rate of $5.0 \mathrm{~g} / \mathrm{min}$, and taken-up at $250 \mathrm{~m} / \mathrm{min}$. The nozzle diameter was $1.0 \mathrm{~mm}$, and the length to diameter ratio was 3 .

\subsection{Drawing}

Fibers were fed continuously from a feed roller, heated by irradiation with a $\mathrm{CO}_{2}$ laser beam, and drawn based on the speed difference between the feed and take-up rollers [12]. The fiber running speed after necking was fixed at $110 \mathrm{~m} / \mathrm{min}$, and the draw ratio (DR) was changed by changing the feeding speed. A random polarized laser beam with wavelength and diameter of $10.6 \mu \mathrm{m}$ and $6 \mathrm{~mm}$, respectively, was generated using a PIN-30R laser (Onizuka Glass Co., Ltd.). The beam was used to irradiate the running fibers from three different directions. The laser power for each drawing condition was determined to enable fluctuations in the neck-drawing point to be minimized. The drawing tension was measured using a tension meter (HS-1500S, Eiko Sokki Co., Ltd.). A 100 gf pickup was installed between the neck-drawing point and the take-up roller. The drawing stress was calculated from the drawing tension and the diameter of the drawn fiber. The drawing conditions are shown in Table 1.

\subsection{On-line measurement}

USAXS images were obtained by X-ray irradiation of the running fiber during the continuous drawing. The on-line measurement system has been described in a previous report [12]. The distance 
from the necking point to the X-ray irradiation position was changed by moving the laser irradiation position. The elapsed time after necking was calculated by dividing the distance by the fiber running speed.

The distance between the necking point and the X-ray irradiation position was measured with a CCD video camera (Watec Co., Ltd. WAT-232S type) that was placed coaxial to the X-ray beam using a mirror. The CCD video camera was equipped with a telecentric lens (OPTART Co., Ltd. TV-2S) with double magnification. The synchrotron X-ray beam used in this study was from SPring-8 BL03XU (FSBL), and an undulator was used to obtain an ultrahigh-intensity X-ray beam. The X-ray beam diameter was $10 \mu \mathrm{m}$, which was obtained through a $9 \mu \mathrm{m}$ defining pinhole (50 mm-thick tantalum). Two pairs of Si crystals were arranged immediately downstream of the pinhole. The Si crystals were arranged vertically and horizontally under conditions that satisfy Bragg's diffraction angle. The parasitic scattering emitted from the defining pinhole was removed by the Si crystals. The Pilatus detector (DECTRIS Co. Pilatus3 S 1M), which has $1043 \times 981$ pixels (172 $\mu \mathrm{m} /$ pixel) was also used. The wavelength of the X-ray beam was $0.155 \mathrm{~nm}$, the camera length was $7564 \mathrm{~mm}$, and the exposure time was $60 \mathrm{~s}$.

Time resolution was calculated using the same calculation method as previously reported [20]. Image processing could not be performed because the image extracted from the necking movie in this experiment was rough and blurred. Therefore, the time resolution was estimated by the length and the fluctuations of the necking with reference to those previously reported [13, 20]. That is, it was estimated that the neck fluctuation was $0.09-0.14 \mathrm{~mm}$, the neck length was $0.13-0.28 \mathrm{~mm}$ for PET fibers, and the neck fluctuation was $0.095 \mathrm{~mm}$, the necking length was $0.06 \mathrm{~mm}$ for PPS, where the size of the X-ray beam was $0.01 \mathrm{~mm}$ and the fiber running speed was $110 \mathrm{~m} / \mathrm{min}$. The estimated time resolution was $0.09-0.17 \mathrm{~ms}$ for PET and $0.06 \mathrm{~ms}$ for PPS.

\subsection{Birefringence}

The birefringence for each fiber was measured by a polarized light microscope (BX51-33POC, Olympus Co., Ltd.) with a monochromic filter of $546 \mathrm{~nm}$. Tricresyl phosphate was used as an immersion oil. The average and standard deviation of birefringence were calculated for 10 samples.

\subsection{Physical properties test}

The thermal and mechanical properties of the drawn fibers were analyzed by tensile tests, thermomechanical analysis (TMA), and differential scanning calorimetry (DSC). The strength, elongation, and Young's modulus were measured by a universal testing machine (Autograph AGS-X, Shimadzu Co. Ltd.) equipped with a 50-N load cell and air chuck. The sample length and elongation rate were $40 \mathrm{~mm}$ and $100 \% / \mathrm{min}$, respectively, and the average and standard deviation of the strength, elongation, and Young’s modulus were calculated for every 10 samples. 
A thermomechanical analyzer (TMA/SS6100, SII Nanotechnology Inc.) was used to measure the thermal shrinkage factor and the shrinkage stress at heating rates of 5 and $10 \mathrm{~K} / \mathrm{min}$, respectively. The sample length was $10 \mathrm{~mm}$ for both measurements. DSC was conducted using a calorimeter (Thermoplus DSC8230, Rigaku Co. Ltd.) with a heating rate of $10 \mathrm{~K} / \mathrm{min}$. Powder cut fibers were used for the sample of DSC measurements.

\section{Result and discussion}

\subsection{Properties and structures of fibers}

The structure and properties of the PET and PPS fibers are shown in Table 1. The birefringence of the as-spun fibers was very small, approximately 0.0001 , because both fibers were spun at the lowest speed at which stable winding could be achieved. The birefringence and tensile strength were increased, while the elongation was decreased with the increase of drawing stress for the PET fibers. It was considered that the larger drawing stress applied to the fiber oriented the molecular chains to the fiber axis, and increased the fiber strength.

\subsection{Neck drawing and fiber temperature}

From Table 1, PET was drawn with DR 4.4, 5.0 and 5.6 and PPS was drawn with DR of 4.3. The drawing stress was 61-188 MPa for PET and 100 MPa for PPS. PPS could be drawn in an extremely narrow drawable range of 4.2 to 4.4 , and thus, was measured only with a draw ratio of 4.3 .

The fiber temperatures around the necking point were estimated. The estimated profile was obtained on the basis of an energy balance equation considering temperature rise by laser irradiation, cooling by heat transfer from the fiber surface, work of plastic deformation by an external force, and the latent heat of crystallization [21]. The heat of crystallization was determined using the heat of fusion of the drawn fibers measured by DSC (Table 1). The crystallization induction time and crystallization rate were assumed, as shown in Table 2, with reference to the results of a previous report [13] and the value obtained by Ide et al. [20]. The estimated fiber temperature is shown in Table 2.

\subsection{USAXS pattern}

The USAXS images obtained by subtracting air scattering are shown in Fig. 1. Fig. 1(a) shows the scattering patterns of each elapsed time and draw ratio, and Fig. 1 (b) and (c) show the typical USAXS scattering pattern for PET and PPS. The horizontal direction of the figure shows the equatorial direction and the vertical direction shows the meridional direction. As shown in Fig. 1 (c), three streaks were observed for the USAXS pattern of PPS, which were meridional and equatorial streaks and total reflection. In addition to the three streaks observed for PPS, a layer-lined streak was observed for PET (Fig. 1 (b)). The extremely strong and thin streak overlapped with the streak of the fibril-sized structure in the equatorial direction. This should be the total reflection from the fiber surface. The total reflection 
could be cut off greatly by made a thinner X-ray beam. Although an X-ray beam approximately 1/6 of the fiber diameter was used in this study, we could not completely prevent the total reflection because the fiber fluctuated slightly along the perpendicular direction to the fiber axis. However, the total reflection could be distinguished clearly from the equatorial scattering because it was so sharp. Its influence was limited in a very narrow range around the equator.

Fig. 1(a) shows the USAXS pattern changing with the elapsed time. The negative elapsed time represents the data before necking, and $0 \mathrm{~ms}$ denotes the image taken at the necking point. Before necking, meridian and equatorial streaks were observed for PPS, while an equatorial streak was observed for the as-spun PET fiber. Upon necking, both equatorial and meridional streak intensities greatly increased. A layer-lined streak and meridional streak also appeared. However, the layer-lined streak for DR 5.6 was unclear. After then, the meridian streak was weakened with elapsed time.

\subsection{Meridional streak}

The meridional intensity profile of the USAXS image is shown in Fig. 2. The measured range of scattering vector $q$ from 0.007 to $0.15 \mathrm{~nm}^{-1}$ corresponds a size of the scattering body of 50-900 nm. A meridian peak at $q_{\text {mer }}$ of $0.012 \mathrm{~nm}^{-1}$ was observed only for PPS at -1.0 - $0 \mathrm{~ms}$, and disappeared after necking. The corresponding size of the period was approximately $500 \mathrm{~nm}$. For both PET and PPS, the intensity of the meridian streak took the maximum immediately after necking. The maximum intensity for PPS was more than 10 times larger than PET, and the intensity increased with the increase of drawing stress for PET. After that, the intensity decreased with the elapsed time for both PET and PPS. However, the streak intensity of the drawn PET fiber was still larger than that for as-spun PET fiber, while the intensity of the drawn PPS fiber became smaller than that before drawing. Furthermore, a broad shoulder appeared around $q_{\text {mer }}=0.03 \mathrm{~nm}^{-1}$ at DR 4.4 and 5.0 for PET, while this was not observed for DR 5.6. The corresponding size for the shoulder was approximately $200 \mathrm{~nm}$.

The meridional peak observed at $-1.0 \mathrm{~ms}$ showed a periodic density fluctuation along the fiber axis in the as-spun PPS fiber. The density fluctuation amplified by the necking was thought to arise from the craze formed in the lower density region. The elongational deformation of necking should form a craze, and the weakening of the meridional streak means the collapse of the craze. The larger intensity increase in PPS, indicating larger amount of craze forming, should be caused by the density fluctuation already formed in the as-spun fiber.

\subsection{Layer-lined streak and equatorial streak}

To analyze this equator and layer-lined streaks, the USAXS image was analyzed as follows. Fig. 3 shows the intensity profiles along the meridional direction $\left(q_{\text {mer }}\right)$. When $q_{\text {mer }}$ exceeded $0.02 \mathrm{~nm}^{-1}$, the peak of the layer-lined streak could be distinguished from the equatorial peak. To separate the components of the equatorial streak and layer-lined streak, the intensity profile was fitted by a 
Gaussian function, as shown in Fig. 4. The layer-lined streak was assumed to be symmetrical to the equatorial axis. Prior to the peak fitting, we deleted several data to eliminate the total reflection. Because the total reflection was far sharper than the equatorial streak, it could be ignored except for the very narrow range of $q_{\text {mer }}$. The deleted data range was $\left|q_{\text {mer }}\right|<0.0037 \mathrm{~nm}^{-1}$ for PET, and $\left|q_{\text {mer }}\right|<$ $0.0055 \mathrm{~nm}^{-1}$ for PPS.

The equatorial profiles obtained by the fitting are shown in Fig. 5. For PET with DR 4.4, the intensity profile of equatorial streak did not change much with the elapsed time, while the intensity clearly increased by the necking for the larger draw ratios. In addition, as it was clearly shown for DR 5.6, the intensity continued to increase, and tended to be saturated at $1.0 \mathrm{~ms}$. In contrast, for PPS, the intensity was drastically increased by the necking, and decreased with the elapsed time. The intensity increase by necking was far larger than the increase observed for PET.

The equatorial streak indicated a density fluctuation of several hundred nanometers perpendicular to the fiber axis, which seemed to be the density difference between so-called fibril and inter-fibrillar void. The larger increase of the streak intensity observed for PPS and the higher ratio drawn PET seemed to indicate the formation of a larger amount of inter-fibrillar voids. In contrast, the intensity decrease should indicate the dissipation of the voids. The large decrease of the PPS intensity seemed to be caused by the dissipation of inter-fibrillar voids formed by the necking. However, although the inter-fibrillar void should also collapse with the elapsed time for PET, it rather increased with time in particular for DR 5.6. This could be explained by the voids formed by the crystallization, which occurred less than $1.0 \mathrm{~ms}$ after necking [13].

The position of the layer-lined peak along $q_{\text {mer }}$ were plotted against $q_{\text {eq }}$ (Fig. 6). The streak appeared immediately after necking, and its position was hardly changed with elapsed time. The position also hardly changed with the draw ratio, but the peak separation became difficult owing to the decrease of the streak intensity, in particular at low $q_{\mathrm{eq}}$. The position of the peak was inclined approximately $20^{\circ}$ from the equator, which was similar to the inclination of the X-pattern observed for SAXS [13]. Therefore, it should not be a simple layer-lined streak, but it can be thought as a meridional shoulder peak observed around $q_{\mathrm{mer}}=0.03 \mathrm{~nm}^{-1}$ overlapped with the X-shaped streak.

\subsection{Fibril-size structure development of PET and PPS}

It is interesting that the USAXS patterns of PET and PPS were different although their SAXS patterns were similar. That is, both of them showed an X-shaped SAXS streak changing to a 4-point pattern [13, 20]. However, only PET showed the layer-lined USAXS streak, and PPS showed a far stronger USAXS meridional streak than PET. The layer-lined USAXS streak of PET can be explained by the fibrillar-shaped smectic phase formed less than $1.0 \mathrm{~ms}$ after necking, and its growing to microfibril [12]. This smectic phase is a metastable structure, first reported by Bonart [22], and has been formed during batch drawing [11] and heat treatment of oriented amorphous PET [23]. The 
smectic phase has also been observed for PEN [24] and PBT [25], although it has not been observed for PPS [20]. The period of $200 \mathrm{~nm}$, corresponding to the layer-lined USAXS streak, can be assumed as the period of layered bundle of a fibrillar-shaped smectic phase of approximately $70 \mathrm{~nm}$ in length [12] and inter-fibrillar molecules. A far stronger meridional streak of PPS should be caused by the periodic density deviation preliminary formed in the as-spun fiber. Because of the density deviation along the fiber axis, craze formation preferentially occurred by necking for PPS, whereas slippage between the fibril-forming molecules preferentially occurred in the PET.

\section{Conclusions}

We analyzed the formation of the fibril-size structure after necking using ultra-small-angle X-ray scattering (USAXS), which enables observation of the void and craze formations. Continuous laserheated drawing and undulator synchrotron radiation are adopted to measure the structural development of poly(ethylene terephthalate) (PET) and poly(phenylene sulfide) (PPS) fibers. PET was drawn with DR 4.4, 5.0 and 5.6 and PPS was drawn with DR of 4.3. The drawing stress was 61-188 MPa for PET and $100 \mathrm{MPa}$ for PPS.

Three streaks were observed for the USAXS pattern of PPS, which were meridional and equatorial streaks and total reflection. In addition to the three streaks observed for PPS, a layer-lined streak was observed for PET. A meridian peak corresponding about $500 \mathrm{~nm}$ period was observed only for PPS before necking. Both fibers show an obvious increase in the meridional streak intensity just after necking, and an increase in the equatorial streak after necking. These increases are distinctive for PPS. Moreover, a layer-lined streak appeared after necking only for PET. The intensity of the meridian streak increased with the increase of draw ratio, whereas the intensity of layer-lined scattering decreased with the increase of draw ratio.

Far stronger meridional streak of PPS should be caused by the periodic density deviation preliminary formed in the as-spun fiber, and the layer-lined USAXS streak of PET can be explained by the periodic bundle of a fibrillar-shaped smectic phase.

\section{Acknowledgments}

This study was supported by Grants-in-Aid for Scientific Research (No. 17K05990 and 16K05910) from the Ministry of Education, Culture, Sports, Science and Technology (MEXT), Japan. Experiments were performed at the SPring-8 synchrotron radiation facility (No. 2016A7213). We thank Edanz Group (www.edanzediting.com/ac) for editing a draft of this manuscript.

\section{Reference}

1) T. Kikutani et al. "Fundamental and Practical Technologies for Nano-structured Polymeric Materials”, CMC press, ISBN978-4-7813-0043-6, (2008), p.56-110. 
2) K. Nitta, Kobunshi Ronbunshu, 73, 3, (2016), 281-293.

3) D.H. Reneker and P.M. Geil, J. Appl. Phys., 31, (1960), 1916.

4) S. Yamaguchi, M. Tatemoto. M. Tsuji, Kobunshi Ronbunshu, 47, 2, (1990), 105-108.

5) K. Nakamae, M. Kotera, K. Iino, Sen’i Gakkaishi, 58, 4, (2002), 99-102.

6) Y. Abe, R. Sakamoto, Kobunshi Ronbunshu, 33, 5, (1976), 263-269.

7) K. Shimamura, S. Murakami, M. Tsuji, K. Katayama, Nihon Reoroji Gakkaishi, 7, 1, (1979), 4246

8) R. Kolb, S. Seifert, N. Stribeck, Zachmann, H.G., Polymer, 41, 2931 (2000)

9) A. Mahendrasingam, C. Martin, W. Fuller, D. J. Blundell, R. J. Oldman, D.H. MacKerron, J. L. Harvie, and C. Riekel, Polymer, 41, (2000), 1217.

10) D. Kawakami, B. S. Hsiao, C. Burger, S. Ran, C. Avila-Orta, I. Sics, T. Kikutani, B. Chu, Macromolecules, 38, (2005), 91.

11) K. Okada, K. Nakata, Y. Higashioji, K. Takahashi, Y. Ohkoshi, T. Kanaya, Kobunshi Ronbunshu, 71, 11, (2014), 593-600.

12) T. Yamaguchi, K. H. Kim, T. Murata, M. Koide, S. Hitoosa, H. Urakawa, Y. Ohkoshi, Y. Gotoh, M. Nagura, M. Kotera, K. Kajiwara, J. Polym. Sci., Polym. Phys., 46, (2008), 2126-2142.

13） R. Tomisawa, T. Ikaga, K.H. Kim, Y. Ohkoshi, K. Okada, H. Masunaga, T. Kanaya, M. Masuda, Y. Maeda, Polymer, 116C, (2017), 357-366.

14） S. Houis, M. Schmid, and J. Lubben, Journal of Applied Polymer Science, 106, (2007), 1757

15) P. Gulgunje, G. Bhat, and J. Spruiell, Journal of Applied Polymer Science, 122, (2011), 3110

16) P. Gulgunje, G. Bhat, and J. Spruiell, Journal of Applied Polymer Science, 125, (2012), 1890

17) P. Gulgunje, G. Bhat, and J. Spruiell, Journal of Applied Polymer Science Part3, 125, (2012), 1693

18） 15. E. Perret, F. A. Reifler, R. Hufenus, O. Bunk, and M. Heuberger, Macromolecules, 46, (2013), 440

19) P. Huo, and P. Cebe, Colloid Polymer Science, 270, (1992), 840

20) K. Ide, T. Ikaga, Y. Ohkoshi, I. Wataoka, M. Masuda, and Y. Maeda, Sen’i Gakkaishi, 70, (2014), 4

21) W. Okumura, T. Yamaguchi, Y. Ohkoshi, Y. Gotoh, M. Nagura, Intern. Polym. Proc., 17, (2002), 124-132.

22) R. Bonart, Kolloid-Z, 213, (1966), 1-11.

23) T. Asano, F. J. Balta Calleja, A. Flores, M. Tanigaki, M. Mina, C. Sawatari, H. Itagaki, H. Takahashi, I. Hatta, Polymer, 40, (1999), 6475-6484.

24) K. H. Kim, R. Aida, Y. A. Kang, T. Ikaga, Y. Ohkoshi, I. Wataoka, H. Urakawa, Polymer, 53, (2012), 4272-4279.

25) T. Konishi, Y. Miyamoto, Polymer, 42, (2010), 349-353. 



\section{Figure legends}

Table 1 Structure and physical properties of the drawn fibers

Table 2 Fiber temperatures estimated for the drawing conditions

Figure 1 (a) USAXS images of PET and PPS fibers at corresponding elapsed times after necking. The elapsed times after necking are noted in the figures. Typical USAXS image of (b) PET fiber with DR 5.6 at $0.1 \mathrm{~ms}$ and (c) PPS fiber with DR 4.3 at 0 ms after necking. $q_{\text {eq }}$ and $q_{\text {mer }}$ are the scattering vectors along equatorial and meridional direction, respectively.

Figure 2 Meridional intensity profiles. (a) PET, DR4.4, (b) PET, DR5.0, (c) PET, DR5.6, and (d) PPS DR4.3. Elapsed times are noted in figures.

Figure 3 Intensity profile along the meridional direction at each $q_{\text {eq }}$ obtained by a PET drawn fiber with DR 4.4 at $0.3 \mathrm{~ms}$ after necking. The $q_{\mathrm{eq}}$ are noted in the figure.

Figure 4 An example of peak fitting for 4.4 times drawn PET fiber at $0.3 \mathrm{~ms}$ after necking. The intensity profile along the meridian direction at $q_{\mathrm{eq}}=0.023$ was fitted by the Gaussian equatorial scattering $\left(I_{e q}\right)$ and symmetrical layer-lined scatterings $\left(I_{l}\right)$ after deleting total reflection influenced data.

Figure 5 Equatorial intensity profiles obtained from peak fitting, like in Figure 3. (a) PET, DR 4.4, (b) PET, DR 5.0, (c) PET, DR 5.6, and (d) PPS DR 4.3. Elapsed times are noted in the figure.

Figure 6 Peak position of the layer-lined streak. Draw ratio (a) 4.4, (b) 5.0 and (c) 5.6. Elapsed times are noted in the figure. 
Graphical abstract
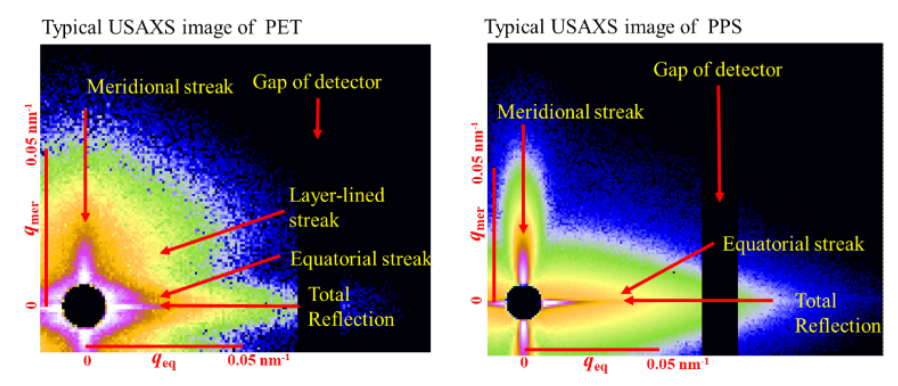

\section{Table 1}

\begin{tabular}{ccccccccccc}
\hline Sample & $\begin{array}{c}\text { Draw } \\
\text { ratio }\end{array}$ & $\begin{array}{c}\text { Drawing } \\
\text { stress } \\
\text { /MPa }\end{array}$ & Birefringence & $\begin{array}{c}\text { Tensile } \\
\text { strength } \\
/ \mathbf{M P a}\end{array}$ & $\begin{array}{c}\text { Elongation } \\
/ \%\end{array}$ & $\begin{array}{c}\text { Young's } \\
\text { modulus } \\
/ \mathbf{G P a}\end{array}$ & $\begin{array}{c}\text { Thermal } \\
\text { Shrinkage temperature } \\
/ \%\end{array}$ & $\begin{array}{c}\text { Melting } \\
/{ }^{\circ} \mathbf{C}\end{array}$ & $\begin{array}{c}\text { Heat of } \\
\text { fusion } \\
/ \mathbf{J} / \mathbf{g}\end{array}$ & $\begin{array}{c}\text { Crystallinity } \\
/ \%\end{array}$ \\
\hline \multirow{2}{*}{ PET } & 4.4 & 61 & 0.165 & 759 & 50 & 9.7 & 16 & 254 & 46 \\
& 5.0 & 105 & 0.179 & 944 & 33 & 10.9 & 19 & 255 & 52 & 34 \\
\hline PPS & 5.6 & 188 & 0.193 & 1087 & 26 & 10.8 & 20 & 256 & 53 & 40 \\
\hline
\end{tabular}

\section{Table 2}

\begin{tabular}{ccccccc}
\hline Sample & $\begin{array}{c}\text { Draw } \\
\text { Ratio }\end{array}$ & $\begin{array}{c}\text { Crystallization } \\
\text { induction time } \\
/ \mathbf{~ m s}\end{array}$ & $\begin{array}{c}\text { Crystallization } \\
\text { rate } / \mathbf{x 1 0}^{\mathbf{3}} / \mathbf{s}\end{array}$ & $\begin{array}{c}\text { Temperature } \\
\text { immediately } \\
\text { before the neck } \\
/{ }^{\mathbf{0}} \mathbf{C}\end{array}$ & $\begin{array}{c}\text { Temperature } \\
\text { immediately } \\
\text { after the neck } \\
/{ }^{\mathbf{0}} \mathbf{C}\end{array}$ & $\begin{array}{c}\text { Max. Temp. } \\
\text { \& Time } \\
/{ }^{\mathbf{0}} \mathbf{C}(/ \mathbf{~ m s})\end{array}$ \\
\hline \multirow{2}{*}{$\mathrm{PET}$} & 4.4 & & & 83 & 109 & $152(2.4)$ \\
& 5.0 & $0.6^{*}$ & $2.3^{*}$ & 100 & 140 & $185(2.3)$ \\
\hline PPS & 5.6 & & & 109 & 180 & $222(2.4)$ \\
\hline
\end{tabular}

*assumed value 


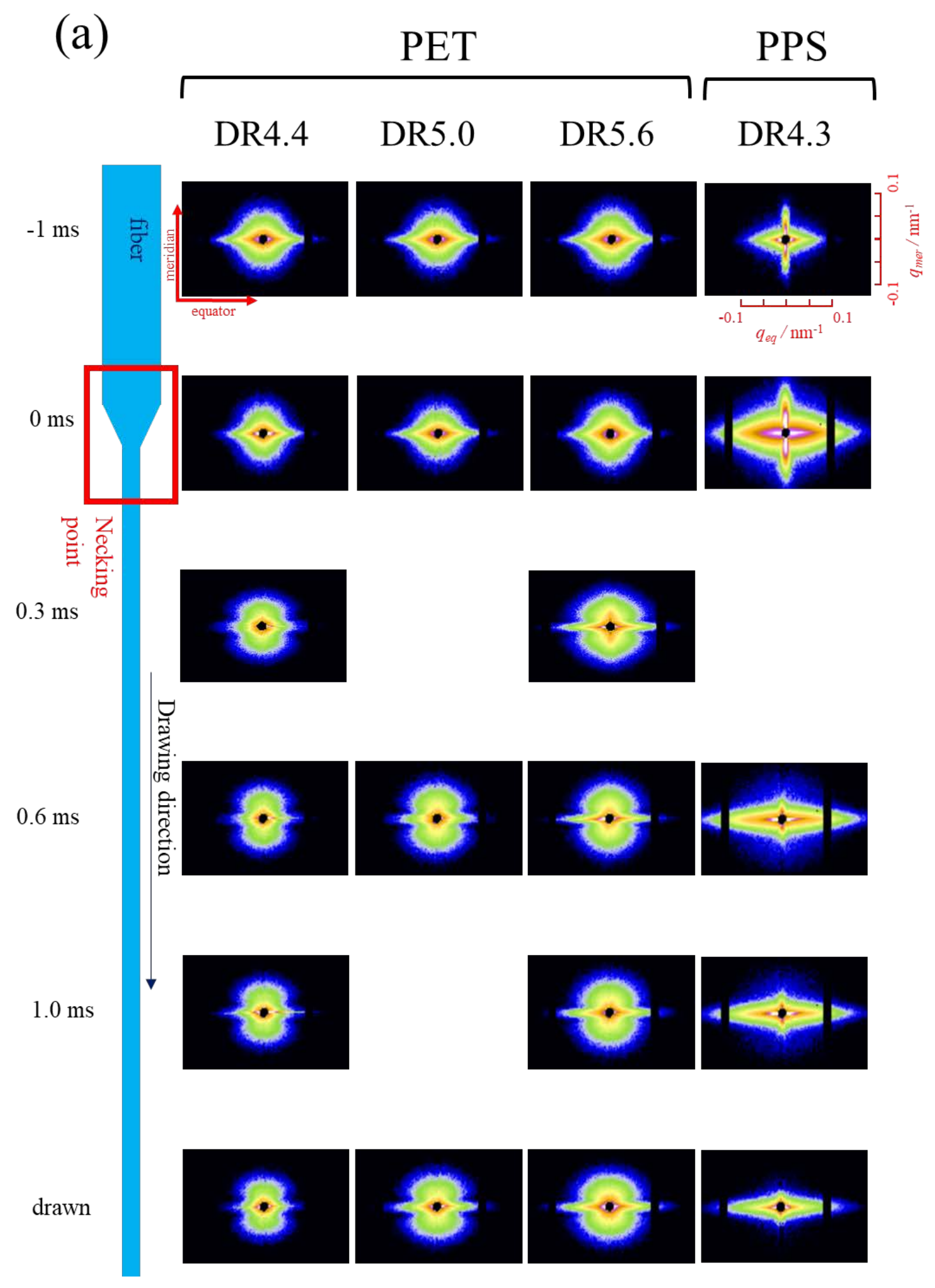

Figure 1 
(b)

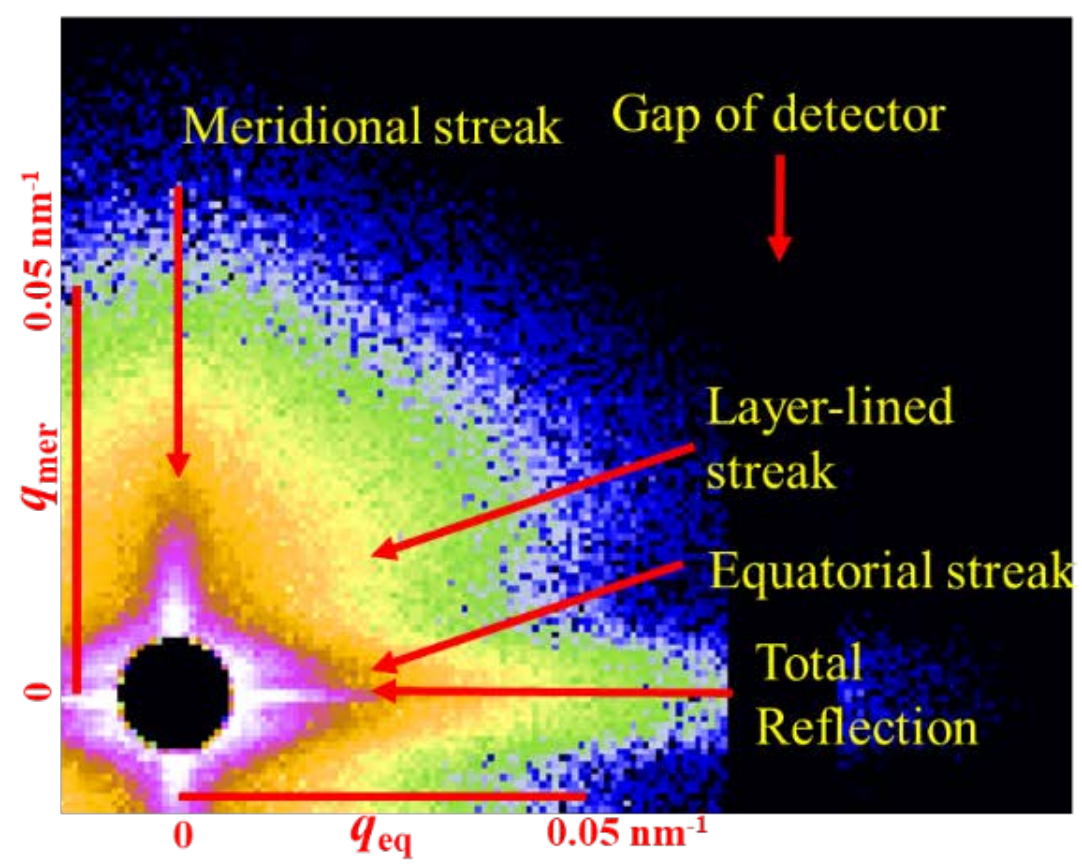

(c)

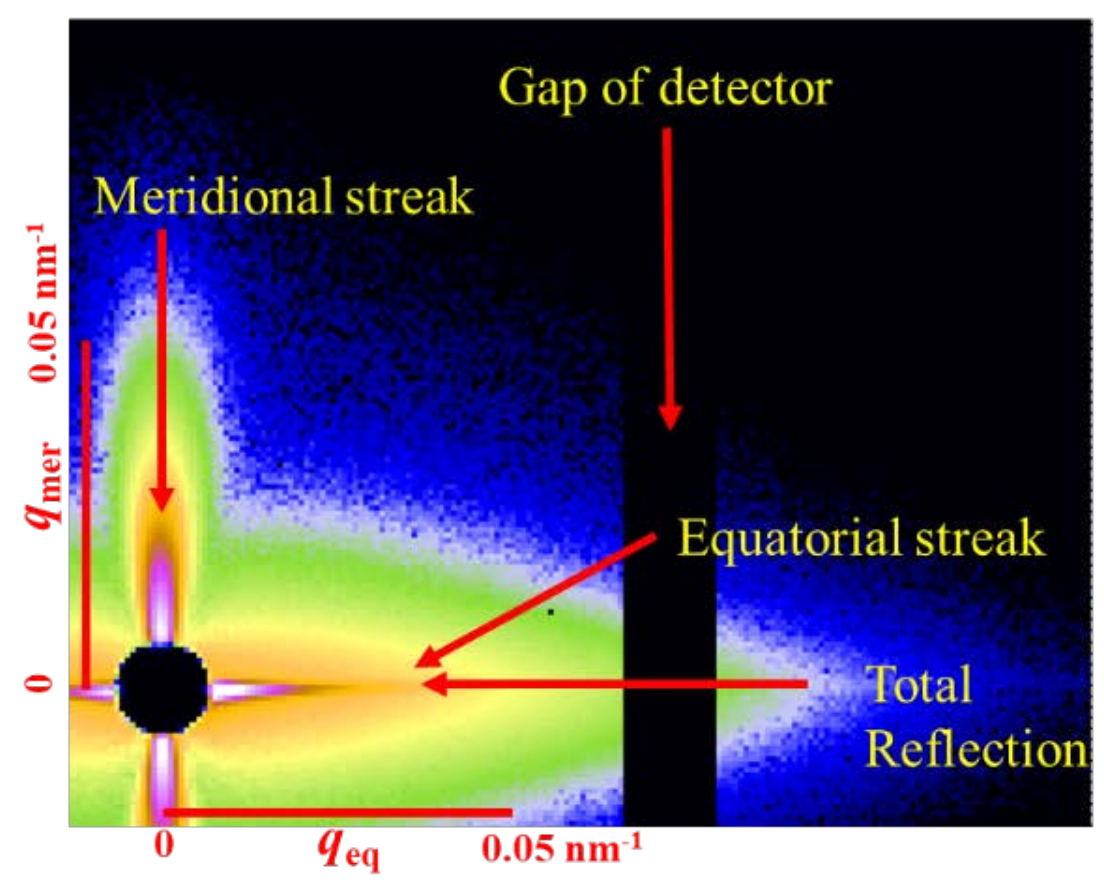

Figure 1 

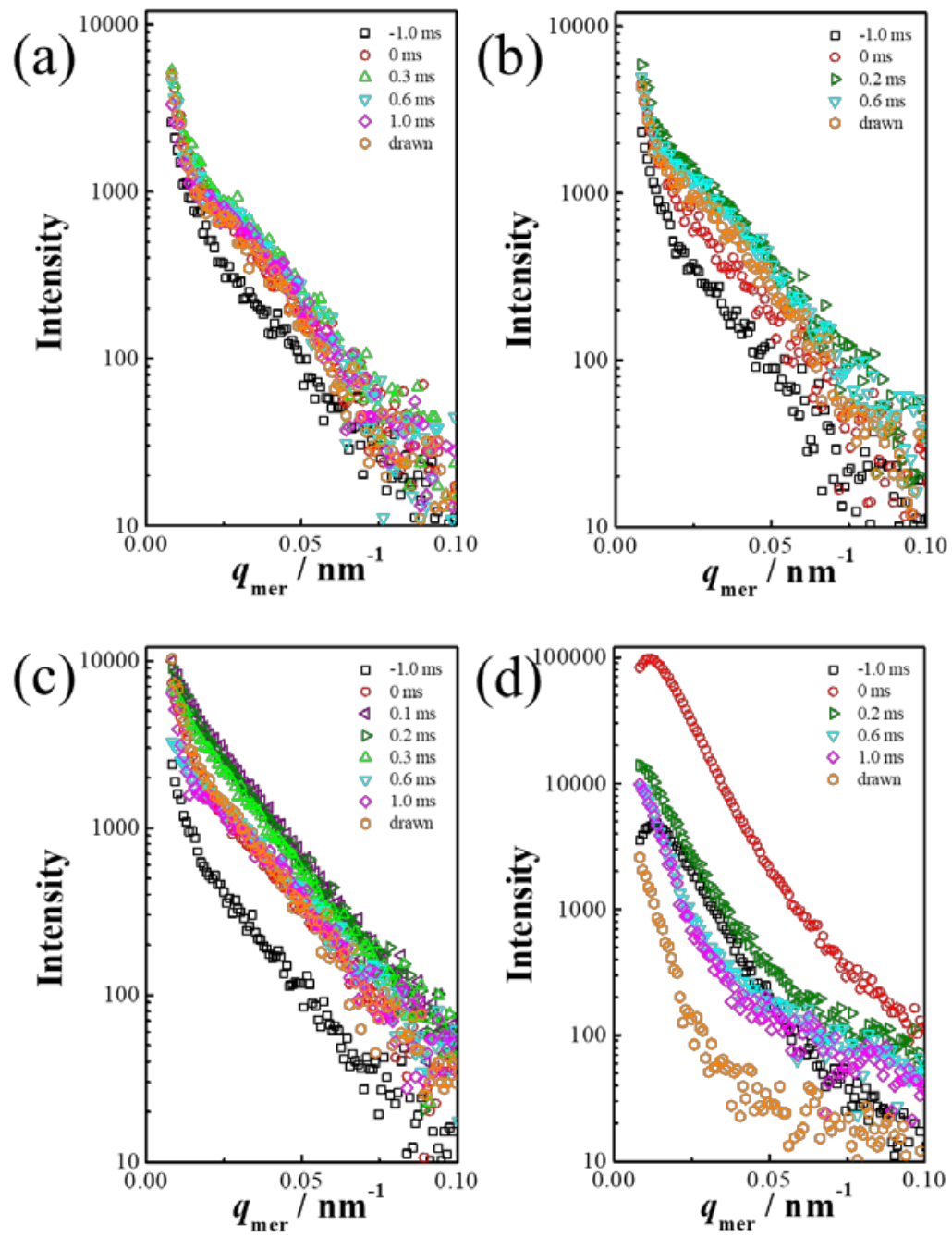

Figure 2 


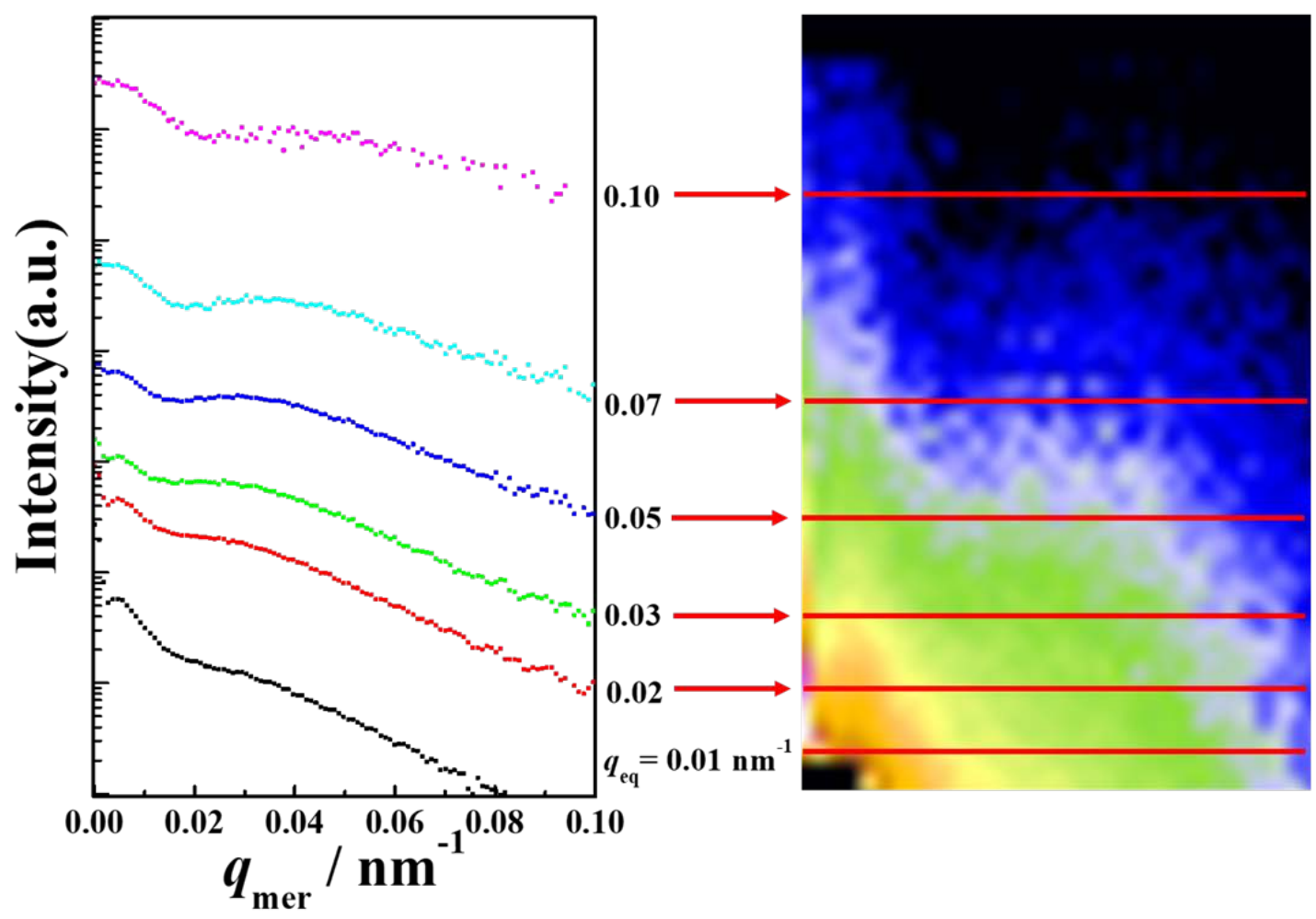

Figure 3 


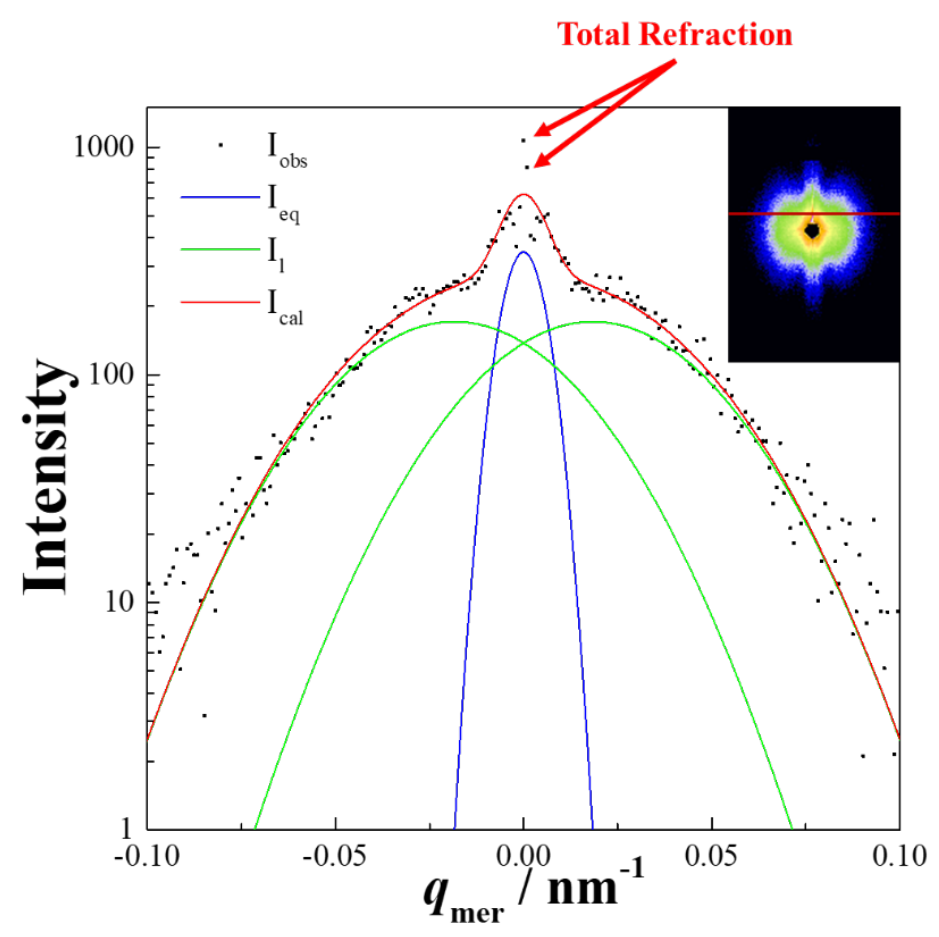

Figure 4 

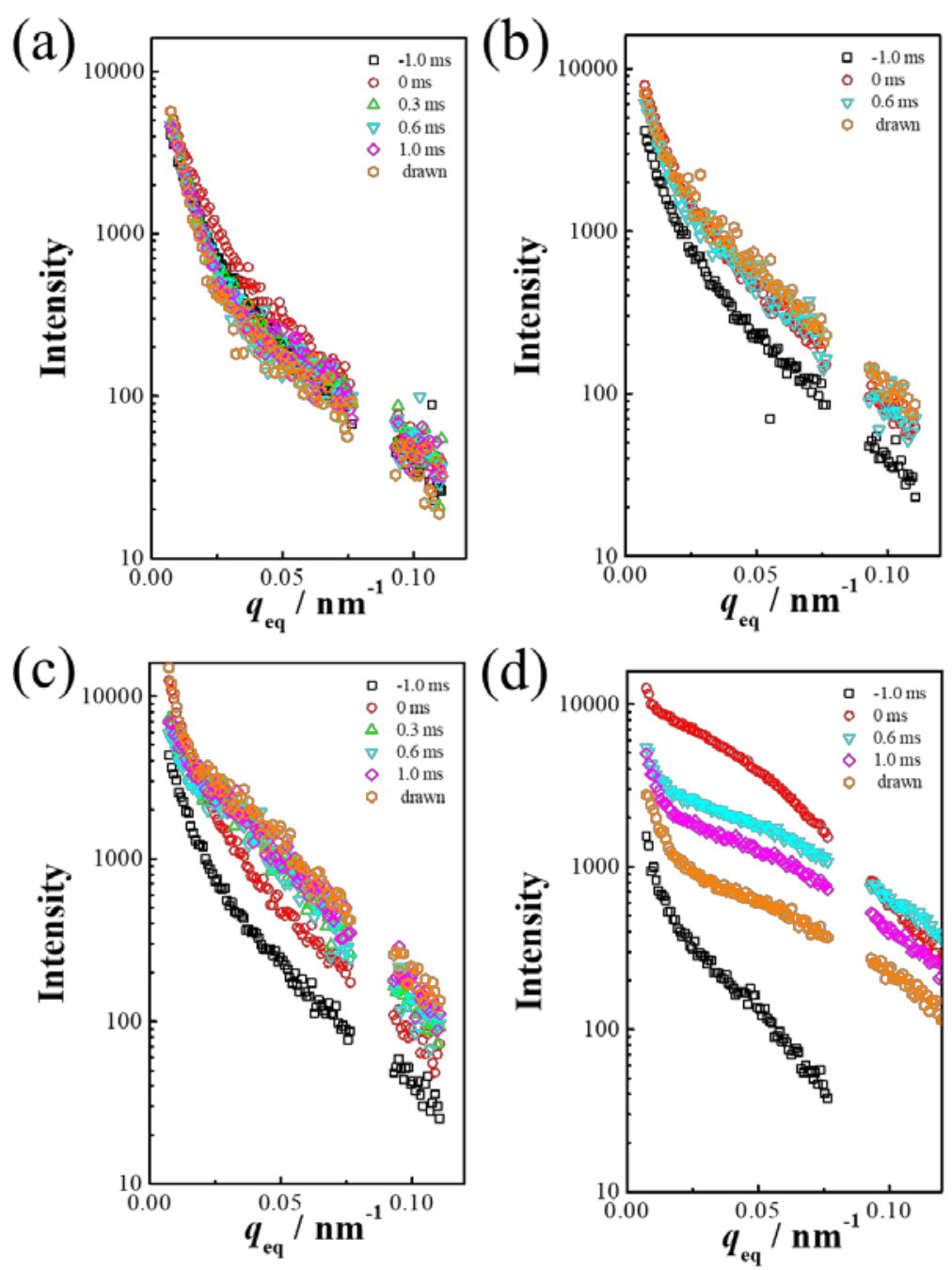

Figure 5 
(a)

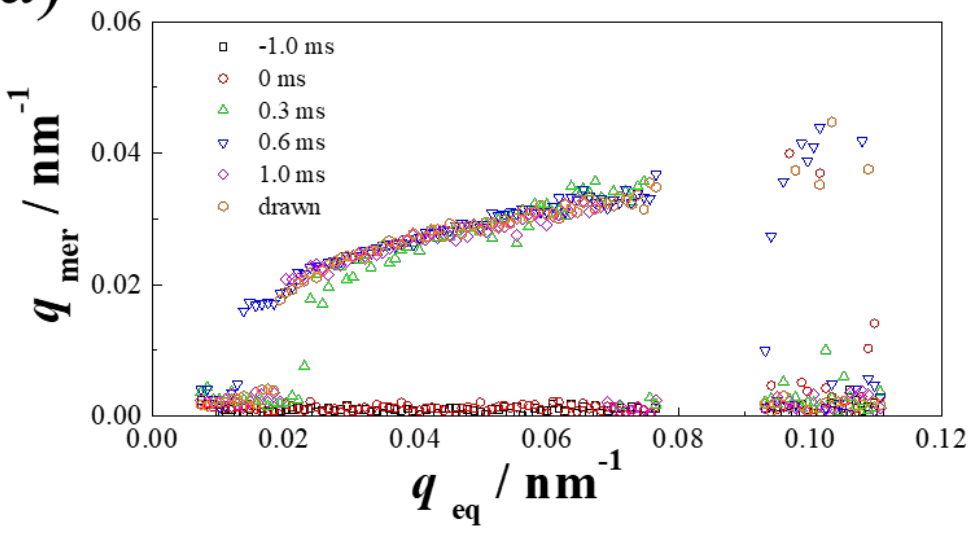

(b)

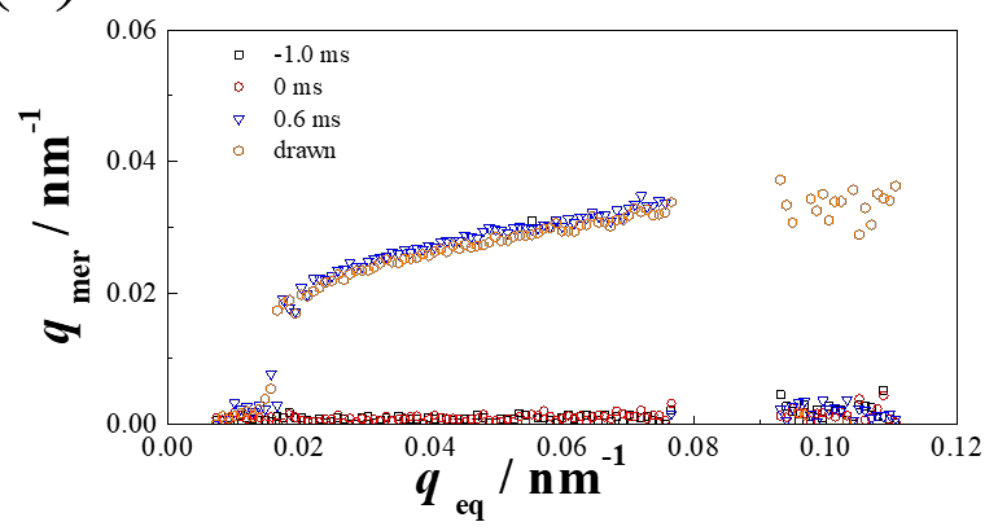

(c)

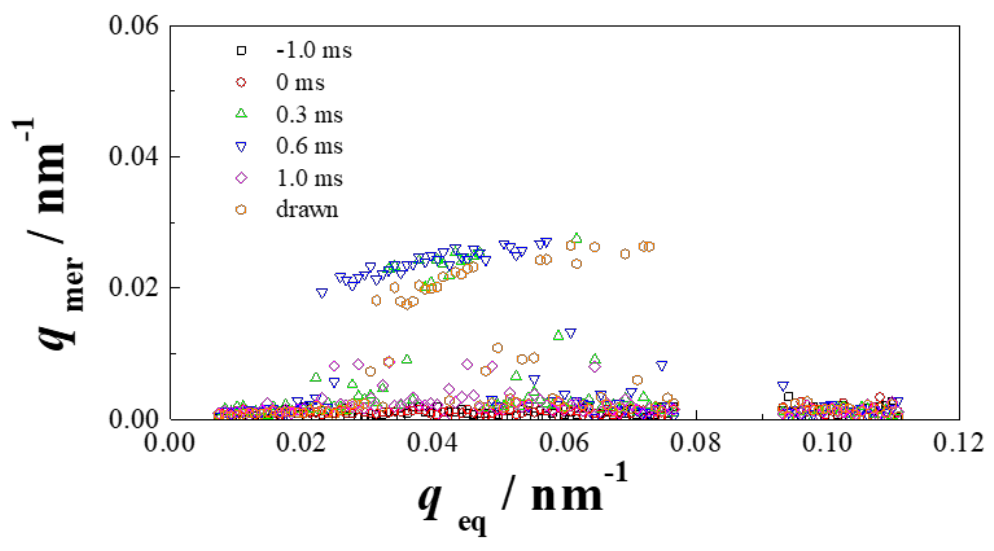

Figure 6 